\title{
As dimensões da prática pedagógica e a escrita de professores: desafios da formação docente
}

\author{
Maria Inês Côrte Vitória* \\ Pontificia Universidade Católica do Rio Grande do Sul \\ Rosa Maria Rigo** \\ Pontifícia Universidade Católica do Rio Grande do Sul
}

Resumo Este artigo apresenta resultados da pesquisa "As dimensões da prática pedagógica e a escrita de professores: desafios da formação docente". Através dos Diários de Aula (ZABALZA, 2004) analisa-se quais dimensões pedagógicas figuram nos Diários dos acadêmicos em estágio do Curso de Pedagogia, assim como converte tais documentos em possibilidade de qualificação da escrita. A metodologia de trabalho seguiu a/o 1) explicitação das características do Diário de Aula; 2) indicação da frequência de escrita do Diário; 3 ) registro do maior número possível de informações; 4) identificação das dimensões pedagógicas; 5) análise da escrita, sob os critérios de: repetição vocabular, ortografia, coesão e coerência textuais; 6) análise dos Diários para acompanhamento dos processos desenvolvidos no Estágio, e avanços na escrita. Alguns resultados acerca das dimensões pedagógicas: 1) o planejamento necessita ser reafirmado como organização do ensino, como previsão, como roteiro; 2) o planejamento necessita figurar como elemento que antecede a aula; 3) o planejamento não é a descrição do que já aconteceu, mas a projeção do que irá acontecer; 4) os objetivos, a metodologia, os recursos, as atividades previstas no planejamento necessitam apontar para o(s) mesmo(s) propósito(s). Acerca da escrita: 1) a escassa utilização de elementos coesivos; 2) o comprometimento da coerência textual; 3 ) as repetições vocabulares; 4 ) os erros ortográficos na escrita de verbos irregulares; 4) a linguagem excessivamente informal.

PALAVRAS-CHAVE: Práticas pedagógicas; Escrita acadêmica; Diários de aula. 


\title{
The dimensions of pedagogical practice and teacher writing: challenges of teacher education
}

\begin{abstract}
This article presents results of the research "The dimensions of pedagogical practice and the writing of teachers: challenges of teacher education". Through the Classical Diaries (ZABALZA, 2004) it is analyzed which pedagogical dimensions are included in the Journal of Academics in the Pedagogy Course, as well as converting such documents into the possibility of writing qualification. The methodology of work followed the 1) an explanation of the characteristics of the Classroom Diary; 2) indication of the writing frequency of the Journal; 3) recording the greatest possible number of information; 4) identification of pedagogical dimensions; 5) analysis of writing, under the criteria of: vocabulary repetition, spelling, textual cohesion and coherence; 6) Analysis of the Diaries to follow the processes developed in the Internship, and advances in writing. Some results about pedagogical dimensions: 1) planning needs to be reaffirmed as an organization of teaching, as a prediction, as a script; 2) Planning needs to appear as an element that precedes the lesson; 3) Planning is not the description of what has already happened, but the projection of what will happen; 4) the objectives, methodology, resources, activities planned in the planning need to point to the same purpose (s). About writing: 1) the scarce use of cohesive elements; 2) the compromise of textual coherence; 3 ) vocabulary repetitions; 4) spelling errors in writing irregular verbs; 4) overly informal language.
\end{abstract}

KEYWORDS: Pedagogical practices; Academic writing; Classroom diaries.

\section{Considerações iniciais}

Este trabalho tem por finalidade apresentar resultados da pesquisa intitulada "As dimensões da prática pedagógica e a escrita de professores: desafios da formação docente", que buscou analisar através dos Diários de Aula (ZABALZA, 2004) quais dimensões pedagógicas figuram nos Diários dos acadêmicos em etapa de estágio do Curso de Pedagogia em uma Universidade Privada do Rio Grande do Sul, assim como converter tais documentos em possibilidade de qualificação da escrita. Nesse sentido, o exercício do registro escrito como apoio à atitude investigativa nos permitiu identificar o conteúdo específico presente nos diários - dimensões pedagógicas - e também mapear e refletir sobre limitações e potencialidades evidenciadas no desempenho linguístico dos estagiários investigados - qualificação da escrita tomando como objeto de análise o próprio diário de aula. A metodologia de trabalho seguiu as etapas de: 1) explicitação das características do Diário de Aula (narrativas sobre o que aconteceu em sala de aula: aspectos objetivos/descritivos e subjetivos/reflexivos), 2) indicação da frequência ( escrever o Diário de aula, no mínimo, 4 vezes por semana); 3) registro do maior número possível de informações; 4) reflexão e identificação das dimensões pedagógicas; 5) trabalho por pares, analisando a qualidade da escrita presente no diá- 
rio, sob os critérios de: repetição vocabular, ortografia, coesão e coerência textuais; 6) análise mensal dos Diários de Aula (em grupo) para acompanhamento dos processos pedagógicos desenvolvidos no Estágio, bem como dos avanços evidenciados na escrita dos estagiários. Nesse sentido, entende-se a formação de professores como um processo contínuo, sistemático e organizado, com aprendizagem igualmente dinâmica e permanente, características que, em geral, ficam mais evidentes ao longo do Estágio Curricular, etapa em que teorias e práticas pedagógicas se vêem em constante relação.

\section{Escrever mais ajuda a escrever melhor?}

Sabemos que nos Diários de Aula o professor explica, expõe e interpreta sua ação diária na aula ou fora dela (ZABALZA, 2004). Na perspectiva do autor, o sentido básico do diário é se tornar um espaço narrativo dos pensamentos dos professores. Ainda para Zabalza (2004), o que se pretende explorar por meio do diário é, estritamente, o que figura nele como expressão da versão que o professor dá sobre sua própria atuação em sala de aula e da perspectiva pessoal através da qual a enfrenta. Dessa maneira, levando-se em conta a existência de um material concreto, ou seja, o texto do diário de aula, pôde-se pensar em convertê-lo, para além de todo um conjunto de possibilidades de reflexões que representa, num valioso instrumento de análise da escrita dos estagiários.

O que se busca com tal dimensão dos Diários de Aula é que o sujeito, através do exercício permanente da escrita, desenvolva formas de intervir na própria escrita, ampliando/aprimorando sua relação com o texto e sistematizando práticas que o levem a considerar a escrita como algo que se tece artesanalmente, através, dentre outros aspectos, da auto-correção, de leituras individuais e em grupo, de pesquisa em dicionários, da organização de glossários, da elaboração de dicionários de sinônimos e ideias afins, e tantos outros dispositivos que uma mediação pedagógica adequada e qualificada pode desenvolver junto aos futuros professores. $\mathrm{Na}$ continuidade deste entendimento mediático, Feuerstein, Feuerstein e Falik (2014) acreditam que a mediação pedagógica cria condições prévias necessárias para que as modificações ocorram. Pela mediação, o professor consegue prover as ferramentas para que o estagiário possa "desafiar-se" e "sentir-se" parte de um processo de transformação que nunca cessa. Portanto, os diários de aula figuram como um ferramental de suma importância para o processo formativo do aluno-professor. Nesse sentido, corrobora Tébar (2011) quando enfatiza a importância da participação ativa do estudante na construção de seu próprio processo de aprendizagem, convertendo-se num sujeito mais autônomo e mais consciente do próprio processo formativo.

A partir desse contexto interpretativo, partimos da premissa de que escrevendo mais se pode escrever melhor. Tal prerrogativa se ampara no fato de que, ao redigir os diários de aula, os estagiários irão se deparar com desafios e dilemas que não enfrentariam caso não estivessem escrevendo. Um exercício reduzido de escrita reduz também a quantidade de dificuldades a serem resolvidas na questão do "como" escrever. Para os participantes da pesquisa, elaborar o diário de aula exigiu uma demanda de tempo, nem sempre possível de se alcançar em meio a tantas atividades que o cotidiano docente apresenta. A validação dos diários de aula como recurso de qualificação 
da escrita somente começou a acontecer quando as primeiras análises gramaticais do texto foram devolvidas ao grupo e discutidas coletivamente, levando-se em conta as indicações feitas ao longo de cada texto sobre aspectos que poderiam ser aprimorados. A escrita, que no início representou para os estagiários uma possibilidade de desvelar erros e inadequações, começou a ser encarada como objeto de estudo, e não apenas como reveladora de limitações, quando o exercício da reescrita passou a fazer parte do cotidiano dos futuros professores. Através de códigos de auto-correção convencionados para identificar a natureza dos problemas da escrita, os próprios sujeitos reelaboravam suas escritas e discutiam sobre os principais entraves que encontraram ao escrever. Nesse movimento permanente de escrita e reescrita, se desenvolveu a ideia de que escrever exige elaboração e reelaboração constantes, contrariando a crença de que escrever bem é um dom. Deste modo, as contribuições do uso do diário como recurso de qualificação da escrita começaram a se delinear nesta investigação a partir de diferentes manifestações dos estagiários sobre o exercício da escrita. Após 4 meses de intenso trabalho de elaboração e reescrita dos diários, podemos considerar que:

- A melhoria da escrita está fortemente ligada à prática de escrever, ao hábito da leitura e ao exercício sistemático da escrita.

- A elaboração do diário de aula é um recurso valioso que ajuda a melhorar a escrita, especialmente quando há indicações específicas sobre o que precisa ser melhorado.

- A escrita mais frequente no cotidiano dos professores-estagiários acontece no envio de bilhetes para os pais, na colocação de recados na agenda dos alunos, no registro do planejamento e na elaboração da avaliação dos alunos.

- A organização e desenvolvimento de ideias é a principal dificuldade encontrada na escrita.

- A ortografia figura como aspecto limitante nos textos dos diários de aula.

- A escrita dos estagiários participantes da pesquisa demonstrou ser exercitada mais por exigência profissional, e menos por prazer de escrever.

- A escrita é uma competência que necessita ser praticada.

- A elaboração dos diários de aula ajuda a melhorar a escrita, embora todos os estagiários refiram a falta de tempo como fator limitante.

Considerando-se as manifestações dos sujeitos da pesquisa e a análise da escrita dos diários, verificou-se que houve, de fato, dificuldade em registrar as situações vividas ao longo do Estágio, em função de que nem sempre o que escreviam correspondia ao que queriam dizer. Identificamos com significativa incidência nos textos dos diários problemas de coesão e coerência textual, de vocabulário, e de ortografia. Verificou-se que foi maior o número de erros pertencentes às irregularidades da norma ortográfica, enquanto os erros pertencentes às regularidades da norma ortográfica foram em menor número. Segundo Morais (2003), a aquisição da ortografia é impulsionada por diversos fatores, tais como a exposição do aprendiz à língua escrita, a frequência de aparecimento das palavras, a regularidade - ou não - da notação ortográfica. 
No entendimento deste estudo, "texto" pode ser qualquer passagem falada ou escrita que forma um todo significativo independente de sua extensão. Trata-se, portanto, de um contínuo comunicativo contextual caracterizado por fatores como: contextualização, coesão, coerência, intencionalidade, informatividade, aceitabilidade, situacionalidade, e intertextualidade. No tocante à coesão e coerência textual, Fávero (2007, p. 60) nos diz que “[...] os fatores de coesão são os que dão conta da estruturação da sequência superficial do texto; e os de coerência, os que dão conta do processamento cognitivo do texto e permitem uma análise mais profunda do mesmo". Assim descrito e especificado parece simples, entretanto, para os estagiários integrantes da pesquisa, escrever de forma a atender as premissas básicas de coesão e coerência não foi tarefa fácil, pois não se tratou apenas de juntar as palavras tomando-as em frases, parágrafos, mas sim de elaborar um Diário de Aula descritivo e reflexivo, traduzido numa escrita objetiva, formal e informativa. O que se pôde observar é que, para os sujeitos da pesquisa, três aspectos emergiram de forma enfática:

1. A ortografia, ao invés de uma aliada, representou um obstáculo ao exercício da escrita. Inúmeros depoimentos orais, trazidos pelos estagiários, ao longo dos encontros semanais durante todo o semestre 2015/II, deram forma às preocupações por eles expressadas da seguinte forma: "professora, eu tenho o que dizer e sei o que quero dizer, só não consigo fazer isso por escrito"...Ou: "Sei o que quero dizer, mas não sei direito como fazer na hora de escrever". E ainda: "Penso numa ideia e acabo por escrever outra"; "Escrevo pouco para errar menos...".

2. A escrita qualificada ainda está associada a uma "dádiva" que se recebe (ou não...), e não a um exercício constante de elaboração e reelaboração. Isso se observou com comentários do tipo: "Não estava inspirado!" "Nunca tive jeito pra escrever". Também aqui se salienta que, embora a discussão oral sobre os registros dos diários de aula tenha sido rica e pertinente, a maneira como a discussão se projetou na escrita ainda deixou a desejar, se levarmos em conta a quantidade de textos pequenos, constituídos de poucos parágrafos, com pouca informação e reflexão.

3. A auto-correção se revelou uma prática pouco utilizada pelos sujeitos da pesquisa. Isso ficou evidenciado nas reelaborações feitas nos diários de aula, quando muitas das indicações feitas pelo professor orientador ao longo do texto, para que este fosse reescrito e aprimorado, retornavam à discussão apresentando os mesmos problemas.

Parece-nos curioso pensar que, embora os estagiários pesquisados reconheçam que escrever é a melhor maneira de qualificar a escrita, todos afirmaram que escrevem somente quando são solicitados a fazê-lo. Ressaltamos também o fato de que os sujeitos da pesquisa declararam não gostar de escrever, pois, para eles, a escrita revela erros e dificuldade por parte de quem escreve. Foi recorrente a afirmação de que a maior dificuldade que encontram, ao escrever, é organizar e desenvolver as ideias. Todos os sujeitos da pesquisa concordam que o Diário de Aula é ótimo instrumento de reflexão e de registro de situações importantes, além de ser um eficaz instrumento para melhorar a própria escrita. Neste sentido, a constância reflexiva, segundo Alarcão 
(2003) é vista como a possibilidade que manterá presente a importante questão da função que os professores desempenham na sociedade e ajudará a equacionar dilemas e problemas futuros. No que concerne à crença equivocada dos estagiários de que escrever é um "dom", recorremos a Mortatti et al,. (2015), ao defenderem a prerrogativa de que escrever não é um dom, mas sim um processo que demanda tempo, dedicação, escritas e re(escritas) sistemáticas. Um desafio que pode ser superado com determinação.

\section{Os diários de aula como instrumento de reflexão sobre as dimensões presentes nas práticas pedagógicas de estagiários do curso de pedagogia}

Os Diários de Aula aqui referendados foram utilizados como instrumento para reflexão acerca das dimensões presentes na prática pedagógica e como recurso para qualificação da escrita do acadêmico em etapa de estágio. A escrita dos diários de aula na perspectiva de Zabalza (2004) permitiu refletir acerca dos desafios que cercam o cotidiano do estagiário imerso em seu campo de atuação/formação e dos recursos linguísticos de que se vale para registrar esse cotidiano. Como metodologia de trabalho o exercício do registro escrito como apoio à atitude investigativa permitiu identificar dilemas que representam entraves à atuação docente no cotidiano de graduandos em etapa de Estágio Curricular Supervisionado, bem como desenvolver um sentido de atuação e capacidade de conduzir a própria aprendizagem. Este estudo visou também buscar maior compreensão e interpretação acerca das atuais tensões e contradições que perpassam o permanente processo de construção do fazer docente. Nesse sentido, convém lembrar que apresentamos ao grupo de estagiários, no início da pesquisa, quatro questionamentos: $\mathrm{O}$ que entendemos por prática pedagógica? $\mathrm{O}$ que entendemos por planejamento? Que dimensões deveriam estar presentes nas práticas pedagógicas? Quais os tipos de planos que conhecemos?

Após a formulação das respostas aos questionamentos, os estagiários foram lendo para o grupo de colegas suas ideias. As ideias principais foram anotadas:

- Previsão do que fazer, método;

- Recurso: organicidade para atingir objetivos;

- Seleção de conteúdos programados a serem trabalhados na sala de aula;

- Roteiro para os passos da aula;

- Tudo que planejamos executar numa determinada atividade;

- Forma de registrar as aulas com os alunos;

- Prática pedagógica são os métodos e técnicas para atingir os objetivos esperados;

- Segurança o que fazer o que pretendíamos;

- Organização do trabalho;

- Planejamento do dia a dia, sem ele seríamos um barco a deriva;

- Prática pedagógica é o que se faz em aula.

Após esta etapa, procuramos conjuntamente, clarear a importância, bem 
como as diferenças entre planejamento, plano e prática pedagógica. Quando pensamos em planejamento temos que ter presente o aluno que temos em aula e o que vamos planejar para este aluno. O planejamento está em nossa cabeça e vem antes. $\mathrm{O}$ plano é o registro escrito que vai acompanhar o professor e que permitirá a ele reconstruir, (re)planejar em função da reflexão realizada a partir da ação. Eu penso no que fiz e reflito sobre esta ação (LOCH, et.al. 2009). Nesse sentido, convém dizer que os estagiários referiram os tipos de planejamento que mais conhecem: plano de curso, plano geral, diário, semanal, quinzenal, mensal anual, semestral, bimestral. Historicamente o planejamento se deu para um tipo de educação bancária, e agora surge uma nova concepção de planejamento que exige adequação à realidade e ao universo do aluno, não sendo, assim, neutro. Sobre isso, alguns conceitos são pertinentes e expressos por Loch et.al. (2009), tais como o planejamento entendido como compromisso com a ação transformadora, como processo mobilizador, como processo organizador, como processo educativo, como processo político e participativo que acontece no interior de uma atividade coletiva. A propósito disso, ficaram evidenciados nos Diários de Aula de todos os estagiários investigados a dimensão que se refere à organização de ensino, sendo que os níveis de planejamento que mais estiveram presentes foram o planejamento educacional de escola e de ensino, o planejamento de longa duração e de curta duração, os temas geradores, os projetos e as sequências didáticas. Outra dimensão presente nos diários de aula se refere aos momentos do ato de planejar. Nesse aspecto figuram o estudo da realidade: pesquisa sócio antropológica - conhecimento de mundo e do aluno - diagnóstico - relação objetivos - conteúdos - procedimentos ou atividades pedagógicas/recursos - avaliação. Nessa perspectiva, o estudo da realidade do aluno através da pesquisa, a escolha das atividades e a avaliação, são etapas fundamentais no planejamento. Exemplo disso é que, num dos diários analisados, o estagiário relata que fez um plano e que quando conheceu a turma teve que mudar todo o seu planejamento. Daí reafirmarmos que somos todos diferentes e por isso cabe ao professor perceber estas diferenças e auxiliar o aluno em seu desenvolvimento. Curioso observar as visões de planejamento dialógico e tradicional evidenciadas nos Diários de Aula, ainda que nem todos os estagiários dominem esta nomenclatura, o que nos faz pensar que muitas dimensões presentes nas práticas pedagógicas se dão mais por intuição e sensibilidade do que por apropriação teórica.

A avaliação aparece nos Diários de Aula como dimensão capaz de classificar o aluno. Sobre isso, refletimos com os estagiários sobre a necessidade de adotar uma visão mais dialógica, mais processual, em que as avaliações não têm o objetivo de classificar, mas sim de identificar o desenvolvimento do aluno, para, a partir desta constatação, utilizar seu conhecimento científico para melhor (re) planejar suas ações pedagógicas. É fato que o aprimoramento constante de práticas pedagógicas que atendam a anseios pessoais aliados às demandas de uma realidade em permanente mudança requer dos estagiários um contínuo exercício de auto-formação, alcançado através de leituras, atualização, grupos de estudo e pesquisa que promovam o alinhamento do futuro professor com o entorno em que atua.

Neste sentido, a utilização dos diários de aula como instrumento de reflexão auxilia o futuro professor a contemplar seu trabalho sobre diferentes perspectivas, servindo de fio condutor para o registro das práticas desenvolvidas, e avaliando o pró- 
prio desempenho profissional numa perspectiva de fomento às dimensões pedagógicas necessárias ao que entendemos por boas práticas de ensino. Ao recorrer às anotações de seu diário de aula o professor tem a possibilidade de refletir em três momentos distintos: "antes durante e depois da ação". Zeichner (1993, p. 18) argumenta que "[...] a ação reflexiva também é um processo que implica mais do que a busca por soluções lógicas e racionais para problemas. A reflexão implica intuição, emoção e paixão [...]”. Não se trata, portanto, de um mero conjunto de técnicas que possa ser repassado aos futuros professores.

Todavia, esta reflexão necessita resultar em ação. A reflexão, por assim dizer, ocupa um lugar de promotora da conscientização, desencadeando possíveis ações. Compartilha com esta linha interpretativa, Schön (2000) ao enfatizar que a aprendizagem ocorre através do fazer, embasando-se nos conceitos de conhecimento na ação e reflexão na ação. Para Shön (2000), o conhecimento na ação está diretamente relacionado com o saber-fazer, é espontâneo, implícito e surge na ação. Sob esta perspectiva a revisão dos apontamentos registrados nos diários de aula podem servir de alicerces para o planejamento e (re)planejamento das ações pedagógicas, reelaborando-as sempre que julgar necessário. É possível que tais readequações possam atingir metas e objetivos mais específicos, ou seja, um recurso precursor para ações docentes mais elaboradas e condizentes com as necessidades contemporâneas.

Faz-se importante ressaltar que outras questões emergiram como necessárias para que o estudo em questão dê continuidade ao processo de aprofundamento da investigação sobre a utilização dos diários de aula como instrumento de reflexão sobre as dimensões presentes nas práticas pedagógicas e como instrumento de qualificação da escrita de acadêmicos em etapa de estágio curricular. São elas:

- O que o acadêmico em etapa de estágio não sabe quando sente dificuldade de organizar e desenvolver as próprias ideias?

- Qual o entendimento do acadêmico em etapa de estágio sobre organização e desenvolvimento de ideias?

- Que aspectos o levam a não gostar de escrever?

- Que encaminhamentos seriam adequados para estimular no acadêmico em etapa de estágio o gosto pela escrita?

- Quais as possíveis razões para a ausência de uma cultura de avaliação formativa nos planejamentos dos estagiários?

- Quais as possíveis razões para a ausência de planejamentos que contemplem o mundo natural e social?

Estas e tantas outras questões poderão ser utilizadas para balizar a continuidade deste estudo em escala ascendente. Refletir é preciso. No desdobramento desta reflexão identificamos um crescente interesse pelo desenvolvimento de métodos pedagógicos que estimulem a aquisição de competências que favoreçam a formação de sujeitos mais reflexivos, mais autônomos, mais criativos. Do ponto de vista clássico a reflexão se refere à capacidade específica do ser humano de fazer de si mesmo e das suas ações objeto de análise. Nesse aspecto, nosso estudo assumiu como objeto de 
análise as dimensões presentes nas práticas pedagógicas dos estagiários, através dos registros nos diários de aula, e a qualificação da escrita deste mesmo registro. Consideramos que este exercício de explorar a escrita dos Diários de Aula como recurso que aprimora nosso fazer docente e nossa forma de escrever sobre ela significou um passo importante dado pelo estagiário em direção a si mesmo.

\section{À guisa de conclusão}

Para finalizar, sem, contudo, encerrar a questão, podemos pensar que os caminhos percorridos no decorrer desta investigação deixam uma porta entreaberta que se associa à capacidade de monitorar a própria prática pedagógica e avaliar os próprios resultados à luz das intenções do nosso propósito educativo. E quanto à escrita? Será através dela que daremos por conhecer nossas histórias vividas desde a sala de aula? De todas as formas, continuamos apostando numa prática pedagógica que desvele dimensões técnicas e éticas. Práticas pedagógicas pautadas numa visão dialógica, que traduza e melhore o contexto no qual nos inserimos, com direito à fala do professor e à fala do aluno. Práticas pedagógicas que levem em conta a linguagem científica e a linguagem da comunidade, o saber popular e a cultura elaborada. Práticas pedagógicas nas quais estejam presentes o processo epistemológico de construção do conhecimento e o processo político de construção da cidadania.

\section{Referências}

ALARCÃO, Isabel. Professores reflexivos em uma escola reflexiva. São Paulo: Cortez, 2003. FÁVERO, Leonor. Lopes. Coesão e Coerência Textuais. Série Princípios, Ed. Ática, São Paulo 2007.

FEUERSTEIN, R; FEUERSTEIN, S. R. FALIK, L H. Além da inteligência: aprendizagem mediada e a capacidade de mudança do cérebro. Petrópolis: Vozes, 2014.

LOCH, Jussara Margareth de Paula. et al. Planejamento, metodologia e avaliação. Porto Alegre: Mediação, 2009.

MORTATTI, Maria do Rosário. L. et. al. Sujeitos da história do ensino de leitura e da escrita no Brasil. São Paulo Editora: UNESP Digital, 2015.

MORAIS, Artur Gomes de. O aprendizado da Ortografia. $3^{a}$ ed. Belo Horizonte: Autêntica, 2003.

SCHÖN, Donald A. Educando o Profissional Reflexivo: um novo design para o ensino e a aprendizagem. Trad. Roberto Cataldo Costa. Porto Alegre: Artmed, 2000.

TÉBAR, Lorenzo. O perfil do professor mediador: Pedagogia da Mediação. Tradução de Priscila Pereira Mota. São Paulo: Senac, 2011.

ZABALZA, Miguel. Diários de aula: um instrumento de pesquisa e desenvolvimento profissional. Tradução Ernani Rosa. - Porto Alegre: Artmed, 2004.

ZEICHNER, Kenneth. M. A Formação reflexiva de Professores: Ideias e práticas. Lisboa, 1993. 
Maria Inês Côrte Vitória - Rosa Maria Rigo

* Professora doutora da Pontifícia Universidade Católica do Rio Grande do Sul, Porto Alegre, Rio Grande do Sul, Brasil.

** Doutoranda em Educação pela Pontifícia Universidade Católica do Rio Grande do Sul, Porto Alegre, Rio Grande do Sul, Brasil.

\section{Correspondência}

Maria Inês Côrte Vitória - Pontifícia Universidade Católica do Rio Grande do Sul, Faculdade de Educação. Av. Ipiranga, 6681, Prédio 15, Partenon. CEP: 90619900. Porto Alegre, Rio Grande do Sul, Brasil.

E-mail:mvitoria@pucrs.br - rosa.rigo01@gmail.com

Recebido em 06 de julho de 2017

Aprovado em 22 de setembro de 2017 